\title{
Assessing sleeping energy expenditure in children using heart-rate monitoring calibrated against open-circuit indirect calorimetry: a pilot study
}

\author{
L. Beghin ${ }^{1,2}$, L. Michaud ${ }^{1}$, D. Guimber ${ }^{1}$, G. Vaksmann ${ }^{3}$, D. Turck ${ }^{1}$ and F. Gottrand ${ }^{1} *$ \\ ${ }^{1}$ Unité de Gastroentérologie, Hépatologie et Nutrition, Clinique de Pédiatrie, \\ Hôpital Jeanne de Flandre et Faculté de Médecine, Lille, France \\ ${ }^{2}$ Centre d'Investigation Clinique, CIC-9301-INSERM-CHU, Hôpital Cardiologique, Lille, France \\ ${ }^{3}$ Service de Maladies Cardiovasculaires Infantiles et Congénitales, Hôpital Cardiologique, Lille, France
}

(Received 31 October 2001 - Revised 26 June 2002 - Accepted 14 July 2002)

\begin{abstract}
Total energy expenditure (EE) can be assessed in children by the heart-rate (HR) monitoring technique calibrated against open-circuit indirect calorimetry (IC). In this technique, sleeping EE is usually estimated as the lowest value of a 30 min resting EE measurement $\times 0.90$ to give an average for the total sleeping period. However, sleeping is a dynamic process in which sleeping EE is modulated by the effect of factors such as body movement and different sleep stages. The aim of the present study was to determine a new method to improve the sleeping EE measurement by taking into account body movements during sleep. Twenty-four nonobese children participated in the present study. All subjects passed through a calibration period. HR and EE measured by IC were simultaneously collected during resting, the postprandial period, and during different levels of activity. Different methods for computing sleeping EE (resting EE $\times 0.90$ with different breakpoints ('flex point' HR with linear regression or 'inflection point' (IP) HR with the third order polynomial regression equation (P3)) were compared with EE measured for least $2.0 \mathrm{~h}$ in eight sleeping children. The best method of calculation was then tested in sixteen children undergoing HR monitoring and with a body movement detector. In a subset of eight children undergoing simultaneous sleeping EE measurement by IC and HR, the use of the equation resting $\mathrm{EE} \times 0.8$ when $\mathrm{HR}<\mathrm{IP}$ and $\mathrm{P} 3$ when HR $>$ IP during the sleeping period gave the lowest difference (1 (SD 5.4) \%) compared with other methods (linear or polynomial regressions). The new formula was tested in an independent subset of sixteen other children. The difference between sleeping EE computed with the formula resting $\mathrm{EE} \times 0.90$ and sleeping $\mathrm{EE}$ computed with resting $\mathrm{EE} \times 0.8$ when $\mathrm{HR}<\mathrm{IP}$ and the P3 equation when HR>IP during sleeping periods was significant (13 (SD 5.9)\%) only for active sleeping subjects ( $n 6$ of 16 subjects). The correlation between the difference in the results from the two methods of calculation and body movements was close $(r 0.63$, $P<0.005$, Spearman test) as well as computed sleeping EE (Spearman test, $r \quad 0.679$, $P<0.001$ ), indicating that this new method is reliable for computing sleeping EE with HR monitoring if children are moving during sleep and improves the total EE assessment.
\end{abstract}

Children: Sleeping energy expenditure: Heart-rate monitoring: Indirect calorimetry

Assessing total energy expenditure (EE) in children under free-living conditions is of interest for research into obesity, metabolic disorders and infective diseases, and to assess overall energy needs (Torun et al. 1996). The method used should be accurate, non-invasive, inexpensive, robust and socially acceptable (Schutz \& Deurenberg,
1996). A method developed by Spurr et al. (1986, 1988), the heart-rate (HR) monitoring technique calibrated against indirect calorimetry (IC), fulfils these criteria and has been validated against reference methods such as the doubly-labelled water method (Emons et al. 1992; Livingstone et al. 1992; Maffeis et al. 1995) and whole-body IC

\footnotetext{
Abbreviations: EE, energy expenditure; FFM, fat-free mass; HR, heart rate; IC, indirect calorimetry; IP, inflection point; P3, third order polynomial equation.

* Corresponding author: Professor F. Gottrand, fax +33 3204459 63, email fgottrand@chru-lille.fr
} 
using calorimetric chambers (Bitar et al. 1996; Treuth et al. 1998). It has also been used in epidemiological studies (Panter-Brick et al. 1996a,b; Wareham et al. 1997). This technique needs a two-step procedure. First, a calibration period (including different activities such as resting, postprandial periods and different levels of physical activity on a cycle ergometer or a treadmill) is carried out with simultaneous recording of HR and EE by IC. This calibration period is used to define an individual regression equation between the HR and EE data. Then, HR is recorded minute-by-minute for $24 \mathrm{~h}$. Finally, EE is compared with the HR results using the regression equation as defined previously.

The major shortcoming of HR monitoring is that this technique is not a good predictor of $\mathrm{EE}$ at low levels of physical activity, especially during sleeping periods. Separation of sleeping periods from the daytime-activity periods contributes to an improvement in the calculation of $24 \mathrm{~h}$ total EE, since for young children in particular, sleep constitutes almost half of the day. Sleeping EE or sleeping metabolic rate computed by a polynomial third-order equation (P3) (Bitar et al. 1996) or a linear regression equation (Treuth et al. 1998) overestimated sleeping EE when compared with IC as a reference method. In fact, $\mathrm{HR}$ is often lower during sleep than during the resting calibration period. Thus, the regression equation should not be used to compute sleeping EE, and the use of predicted BMR or resting EE to estimate the cost of sleep results in an overestimation of $14 \%$ (Geissler et al. 1986; Goldberg et al. 1988). Several recent studies permit determination of the BMR with a good precision in children. It is well established that the sleeping EE is $5 \%$ less than the BMR in adults and $10 \%$ less in children (Astrup et al. 1990; Bitar et al. 1996, 2000; Klausen et al. 1997; Beghin et al. 2000; van Mil et al. 2000).

The use of the equation sleeping $\mathrm{EE}=$ resting $\mathrm{EE} \times 0.90$ to determine an average estimate of the sleeping EE has been shown previously to be a good predictor of sleeping EE in healthy children (Astrup et al. 1990; Bitar et al. 1995, 2000; Klausen et al. 1997; Beghin et al. 2000; van Mil et al. 2000). However, this equation gives a fixed sleeping EE value that cannot take into account the changes in sleeping EE depending on sleep stages and especially nightly body movements. During the course of a night, two different types of sleep alternate, called nonrapid-eye movement and rapid-eye movement sleep (Rechtschaffen \& Kales, 1968), while sleeping EE fluctuates (Brebbia \& Altshuler, 1965, 1968; Haskell et al. 1981; Fontvieille et al. 1994). Moreover, this equation cannot take into account other factors modifying sleeping $\mathrm{EE}$, such as body movements, thermal conditions, postprandial EE, hormone secretions and infectious diseases that could occur during the night and be detected by HR variations. The equation sleeping $\mathrm{EE}=$ resting $\mathrm{EE} \times 0.90$ should only be considered as an average estimate of sleeping EE over the total sleeping period. The need for a precise measurement of sleeping EE is particularly interesting in several situations, e.g. enteral or parenteral nutrition (where energy is usually infused during the night into children at home) or in children who have increased body movements during sleep (sleeping disturbance, neurological, genetic or psychiatric diseases). The purpose of the present study was to find a more accurate method to compute sleeping EE using HR data and, in particular, a method that would take body movement during sleep into account.

\section{Subjects and methods}

\section{Subjects}

Twenty-four non-obese children volunteered to participate in the present study. The first group (eight children) participated in simultaneous recording of nocturnal IC and HR (six boys and two girls aged 8.9 (SD 3.0) years, and a second group of sixteen children was studied for validation of the new method; they were only assessed over a $24 \mathrm{~h}$ period using HR monitoring (twelve boys and four girls aged 8.7 (SD 2.7) years. Children were recruited from the children of the hospital workers. Before the study began, the purpose and the objectives were carefully explained. All volunteers, having passed a thorough physical and medical examination, were considered free from any acute conditions (such as infections) known to affect EE. Written informed consent was obtained from both children and parents and the study was approved by the Lille University Research Ethics Committee (Comité Consultatif de Protection des Personnes dans la Recherche Biomédicale de Lille).

The weights and heights of the subjects (8.8 (SD 2.9) years, $28.4(\mathrm{SD} 8.1) \mathrm{kg}, 1.288$ (SD 0.132) m) were all within the normal ranges of the French population (Sempé et al. 1979) and there were no differences in the eight subjects undergoing sleeping EE measurement by simultaneous IC and HR monitoring and the sixteen in which sleeping EE was only computed with two different methods. Body resistance was measured using a body impedance meter $(50 \mathrm{~Hz}$, BIA $101 / \mathrm{S}$; RJL Systems, Detroit, MI, USA) and fat-free mass (FFM) was calculated using the Schaefer formula (Schaefer et al. 1994).

\section{Energy expenditure}

EE was measured by IC, using an open-circuit ventilated hood system (Deltatrac II; Datex Instrumentation Corporation, Helsinki, Finland). Validity and accuracy of expired $\mathrm{CO}_{2}\left(V_{\mathrm{CO}_{2}}\right)$ and inspired $\mathrm{O}_{2}\left(V_{\mathrm{O}_{2}}\right)$ flows and the RER were checked and calibrated by reference to alcohol combustion every 6 months according to the calorimeter's manufacturers (Datex Instrumentation Corporation). The manufacturers (Datex Instrumentation Corporation) certified a $\mathrm{CV}<2 \%$ for each measurement of $V_{\mathrm{CO}_{2}}$ and $V_{\mathrm{O}_{2}}$ flows and the RER.

Before each test, the calorimeter was calibrated with a reference gas mixture $\left(\mathrm{CO}_{2}-\mathrm{O}_{2}(5: 95, \mathrm{v} / \mathrm{v})\right.$; Datex Instrumentation Corporation). EE was calculated every minute from $V_{\mathrm{O}_{2}}(\mathrm{ml} / \mathrm{min})$ and $V_{\mathrm{CO}_{2}}(\mathrm{ml} / \mathrm{min})$ using the Weir formula (Weir, 1949) without correction for protein.

After an adaptation period of 15 min under the transparent ventilated canopy system, continuous respiratory exchange measurements were initiated. During the first calorimetric measurements, the child rested quietly while watching videotapes or reading in dorsal decubitus. Special 
care was taken to prevent spontaneous movements that might increase EE. All events occurring during the test were recorded on a logbook, so that only steady state values were taken into account for analysis. The resting $\mathrm{EE}(\mathrm{kJ} / \mathrm{h})$ at steady state was calculated using the Weir formula (Weir, 1949). It was defined as CV $<10 \%$ for both $V_{\mathrm{O}_{2}}$ and $V_{\mathrm{CO}_{2}}$ and $<5 \%$ for RER. Postprandial EE was then measured after a non-standardized breakfast (1497 (SD 422) $\mathrm{kJ}$ ) and EE was then measured during calibrated exercises.

Sleeping EE measured by IC was also recorded during a period of at least $2 \mathrm{~h}$ between 22.00 and 04.00 hours, simultaneously with HR monitoring, after a fasting period of up to $5 \mathrm{~h}$. In our present study, care was taken to keep the child asleep during sleeping EE measurement. The calorimeter was turning on $5 \mathrm{~h}$ before the sleeping EE measurement started at home in the bedroom. He was invited to read a book or watch videotapes during the $2 \mathrm{~h}$ before the sleeping period to habituate him to the presence of the equipment. Moreover, after he was asleep, an investigator was present in the room to check the validity of the procedure (both sleeping state and measurement quality) during all the sleeping EE measurements.

\section{Heart rate monitoring}

The equipment used for HR monitoring was a Holter 24 or $48 \mathrm{~h}$ recorder with two channels of electrocardiographic data (Synesis; ELA Medical, Montrouge, France). The HR values, defined as the mean of the HR recorded every minute over the specific period, were calculated with Synetec software (version 1.1; ELA Medical).

\section{Timing of measurements and programme of activities of the calibration period}

On the day of the test, the child arrived by car at the Clinical Investigation Centre of Lille Medicine University Hospital (CIC-9301-INSERM-CHU) at 08.00 hours, having fasted from 20.00 hours the day before. Weight and height were measured. The child was fitted with probes for continuous recording of $\mathrm{HR}$ using an $\mathrm{Ag}-\mathrm{AgCl}_{2}$ electrode. After an adaptation period of 15 min under the ventilated canopy system, continuous respiratory exchange measurements were made for $30 \mathrm{~min}$, with the child remaining recumbent.

Postprandial EE and HR were then measured (preceded by a new adaptation period of $15 \mathrm{~min}$ with the canopy positioned over the head) $1 \mathrm{~h}$ after a non-standardized breakfast.

EE was also determined at different levels of calibrated physical exercise. These consisted of cycling on a cycle ergometer (Philips, Paris, France), beginning at $5.0 \mathrm{~W}$ and increasing the braking force every $30 \mathrm{~s}$ by $2.5 \mathrm{~W}$ to obtain a maximal HR close to the theoretical maximal heart frequency $(220$ - age (years)). After this calibration period, children were fitted with probes for a $24 \mathrm{~h}$ continuous HR recording during a school day without sporting activities.

\section{Computing the sleeping energy expenditure}

Two methods were used to compute sleeping EE: linear regression or P3. For the first method, a two-phase individual crossover linear regression with a breakpoint called the flex point was used to compute sleeping EE in each subject according to previous published methods. The flex point was defined as the mean HR value of the five highest HR values during rest and the five lowest $\mathrm{HR}$ values measured during the postprandial period or during exercise (Spurr et al. 1986, 1988; Livingstone et al. 1992). Two linear regression equations were calculated: linear equation 1 and linear equation 2 as shown in Fig. 1. Sleeping EE was computed using linear regression equation 1 when HR was below the flex point and linear regression equation 2 when HR was above the flex point. The second method of calculation was an individual HR $v$. $\mathrm{EE}$ regression equation with a $\mathrm{P} 3$ describing the relationship $\mathrm{HR} v$. $\mathrm{EE}\left(\mathrm{EE}=a \times \mathrm{HR}^{3}+b \times \mathrm{HR}^{2}+c \times \mathrm{HR}+d\right.$, where $a, b, c$ and $d$ are numeric factors as shown in $\mathrm{P} 3$ in Fig. 1) (Beghin et al. 2000). A threshold HR called inflection point (IP) was defined to discriminate the use of a multiple of resting EE or the P3 to compute sleeping EE from HR monitoring. The IP was defined by the following equation:

$$
\mathrm{IP}=(-\beta-\sqrt{ } \delta) / 2 \alpha,
$$

where $\delta=\beta^{2}-4 \alpha \chi$ (derived equation of $\mathrm{EE}^{\prime}=\alpha \mathrm{HR}^{2}+$ $\beta \mathrm{HR}+\chi$, where $\alpha=3 \times a, \beta=2 \times b, \chi=c$; from the $\mathrm{P} 3$ equation $\left.\mathrm{EE}=a \times \mathrm{HR}^{3}+b \times \mathrm{HR}^{2}+c \times \mathrm{HR}+d\right)$.

Several equations were tested: resting $\mathrm{EE} \times 0.95$, resting $\mathrm{EE} \times 0.90$, resting $\mathrm{EE} \times 0.80$, or resting $\mathrm{EE} \times 0.75$ when $\mathrm{HR}<\mathrm{IP}$ and P3 when HR $>$ IP. The use of resting EE $\times$ 0.80 in the new formula was finally chosen to compute sleeping EE, giving the lower difference between the new method and resting $\mathrm{EE} \times 0.90$ as reference (results not shown). Thus, sleeping EE was computed by resting $\mathrm{EE} \times 0.80$ when $\mathrm{HR}<\mathrm{IP}$ and with $\mathrm{P} 3$ when $\mathrm{HR}>\mathrm{IP}$.

\section{Detection of body movements during sleep}

Total body movements were measured during the night by a TriTrac-R3D accelerometer (Professional Products, Reining International, Madison, WI, USA). The device measures acceleration in three individual planes and integrates acceleration to yield a single value termed 'vector magnitude' (the square root of the sum squared of activity counts in each vector) (Bouten et al. 1994, 1997; Westerterp, 1999). The use of TriTrac-R3D equipment has been shown to be reliable (Welk \& Corbin, 1995; Coleman et al. 1997) and accurate (Jakicic et al. 1999; Masse et al. 1999) for detecting body movement. It was worn attached to the anterior torso of the subject at the level of the waist, perpendicular to the mid-line of the anterior thigh.

\section{Statistical analysis}

Variables were compared either using the non-parametric Wilcoxon rank test (where significant difference was defined as $P<0.05$ ) and correlations were tested by Spearman test using SPSS 7.0 for Windows (SPSS, Chicago, IL, 


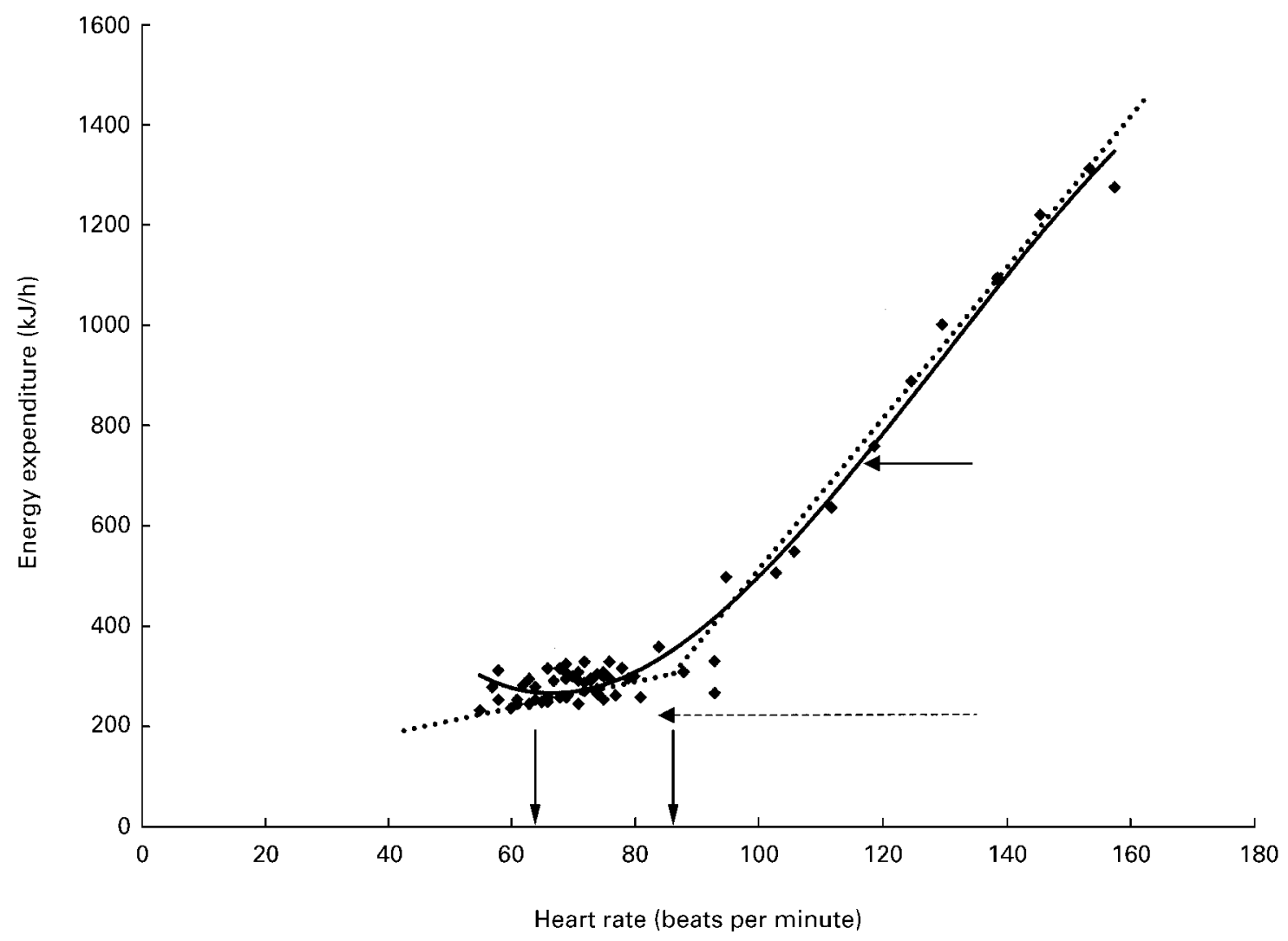

Fig. 1. Example of regression line of energy expenditure measured by indirect calorimetry $v$. heart rate with the flex point and the inflection point in a representative subject. For details of procedures, see p. 534. $\downarrow$, Inflection point (66 beats per $\mathrm{min}$ ) and flex point ( 88 beats per $\mathrm{min}$ ); $4--$, linear equation 1 (energy expenditure $=1.73$ heart rate + 183.03); $\leftarrow$, linear equation 2 (energy expenditure $=13.99$ heart rate +879.73 . Third order polynomial equation: energy expenditure +-0.0013 heart rate ${ }^{3}+0.51$ heart rate $^{2}-50.96$ heart rate +1787.8 .

USA). Agreements between methods for determining EE were assessed using the Bland-Altman method (Bland \& Altman, 1986). The lack of agreement between methods can be evaluated by calculating the bias, estimated from the mean difference and the standard deviation of the difference in the precision of the individual regression equations.

\section{Results}

Comparison of sleeping energy expenditure using different methods $\mathrm{v}$. indirect calorimetry in eight children

Eight children participated in both HR monitoring and IC during sleeping. Values for IP and flex point in each subject and values for sleeping EE obtained with different methods were compared with sleeping EE measured by IC in Table 1. The mean difference between predicted sleeping $\mathrm{EE}$ by resting $\mathrm{EE} \times 0.80$ plus the $\mathrm{P} 3$ equation method or resting EE $\times 0.90$ method and measured sleeping EE were close (1.0 (SD 5.4) and 1.6 (SD 6.0) \% respectively). The other methods gave higher mean percentage difference compared with measurement by IC. The degree of agreement between sleeping EE measured by IC and sleeping EE computed with the method resting $\mathrm{EE} \times 0 \cdot 8+\mathrm{P} 3$ is shown as a Bland-Altman plot in Fig. 2. All values of sleeping EE lie within the limits of agreement
$( \pm 2 \mathrm{SD}$ of the mean difference between the two methods (mean value $3 \cdot 1$, range $-16 \cdot 2-22.5 \mathrm{~kJ} / \mathrm{h}$ )). These results shown that the two methods are close.

Comparison of sleeping energy expenditure using both methods in sixteen children

Sixteen children participated only in HR monitoring and in wearing the accelerometer during sleeping period. As shown in Fig. 3, differences between the two methods were significantly correlated with body movements ( $r 0.63, P<0.005)$. Differences between the two methods were $<5 \%$ when body movements were no more than 6000 vector magnitude 'counts'. This cut-off point was used to distinguish less active from active children during the sleeping period.

Table 2 shows a comparison of sleeping EE assessed with the 'resting $\mathrm{EE} \times 0.80$ plus $\mathrm{P} 3$ equation' and 'resting $\mathrm{EE} \times 0.90$ ' equations, according to body movements in the sixteen patients only studied with HR monitoring. The mean difference in sleeping $\mathrm{EE}$ assessed with the 'resting $\mathrm{EE} \times 0.80+\mathrm{P} 3$ ' and the 'resting $\mathrm{EE} \times 0.90$ ' equation for total data was $>5 \%(5.4(\mathrm{SD} 7.3) \%)$ and this difference was significant $(P<0.05)$. When body movements were $<6000$ vector magnitude 'counts', there was no difference in sleeping $\mathrm{EE}$ assessed with both 
methods: the difference was $<1 \%(0.8$ (SD 2.6) \%). In contrast, when children had higher body movement during sleep ( $>6000$ vector magnitude 'counts'), the difference between the two methods was high and significant (13 (SD 5.9) \%, P<0.05).

Fig. 4 shows the high correlation between body movement and sleeping $\mathrm{EE}(\mathrm{kJ} / \mathrm{min}$ per $\mathrm{kg}$ FFM) for sixteen children (Spearman test, $P<0 \cdot 01$ ).

Fig. 5 shows the pattern of variation in sleeping EE computed with the new formula according to body movement for a more active subject (subject with 15684 vector magnitude 'counts' during sleep).

Table 3 shows total EE obtained in our present study by the HR method using the two modes of calculation. Total EE computed with the 'resting $\mathrm{EE} \times 0 \cdot 80+\mathrm{P} 3$ ' and 'resting $\mathrm{EE} \times 0.90^{\prime}$ modes of calculation were not different $(7027$ v. $6785 \mathrm{~kJ} / \mathrm{d})$. However, individual variations were great (range $-0.5-17.9 \%$ ).

\section{Discussion}

A number of studies have used BMR or resting EE predicted by Benedict's (1919), Talbot's (1921), Karlberg's (1952), Schofield's (1985) or the Food and Agriculture Organization/World Health Organization/United Nations University (World Health Organization, 1985) equations to assess sleeping EE or sleeping metabolic rate. These equations do not take into account factors influencing sleeping metabolic rate in children (Eccles et al. 1989) and the large range of sleeping $\mathrm{EE}$ in children (Azaz et al. 1992; Butte et al. 1992; Wells \& Davies, 1995a,b; Hull et al. 1996). Most of the published studies showed an influence of sleep stage on sleeping EE (Brebbia \& Alshuler, 1965, 1968; Rechtschaffen \& Kales, 1968; Webb \& Hiestand, 1975; Stothers \& Warner, 1978, 1984), although a few did not show a difference (Palca et al. 1986; Hull et al. 1996), but no results are available for body movement during sleep. There is general agreement among authors that $V_{\mathrm{O}_{2}}$ decreases during the first part of the night, reaches a nadir, and then starts to rise toward morning (White et al. 1985; Ryan et al. 1989). Moreover, the effect of clock time and the effect of sleep stages differed between subjects (Brebbia \& Altschuler, 1968). These observations indicate that measurement of total EE in children should include an individual and specific calculation mode of sleeping EE. Moreover, body movement during sleep could increase sleeping EE.

In a previous study, we showed that the sleeping EE computed with the resting $\mathrm{EE} \times 0.90$ equation was not different from sleeping EE measured by IC (Beghin et al. 2000). Our present pilot study confirms this finding using measurement of IC compared with HR monitoring in eight motionless subjects; the mean difference between both methods was $<2 \%$ (Table 1 ).

The RER of 0.8 (SD 0.2) measured in our present study (results not shown) was in agreement with previous studies (Haskell et al. 1981; Palca et al. 1986; Bracco et al. 1996). Sleeping EE was measured by IC for at least 2.0 (range $2 \cdot 0-2.5) \mathrm{h}$ between 22.00 and 04.00 hours. We chose this period, because as shown by Fontvielle et al. (1994), the lowest sleeping EE values are obtained between 


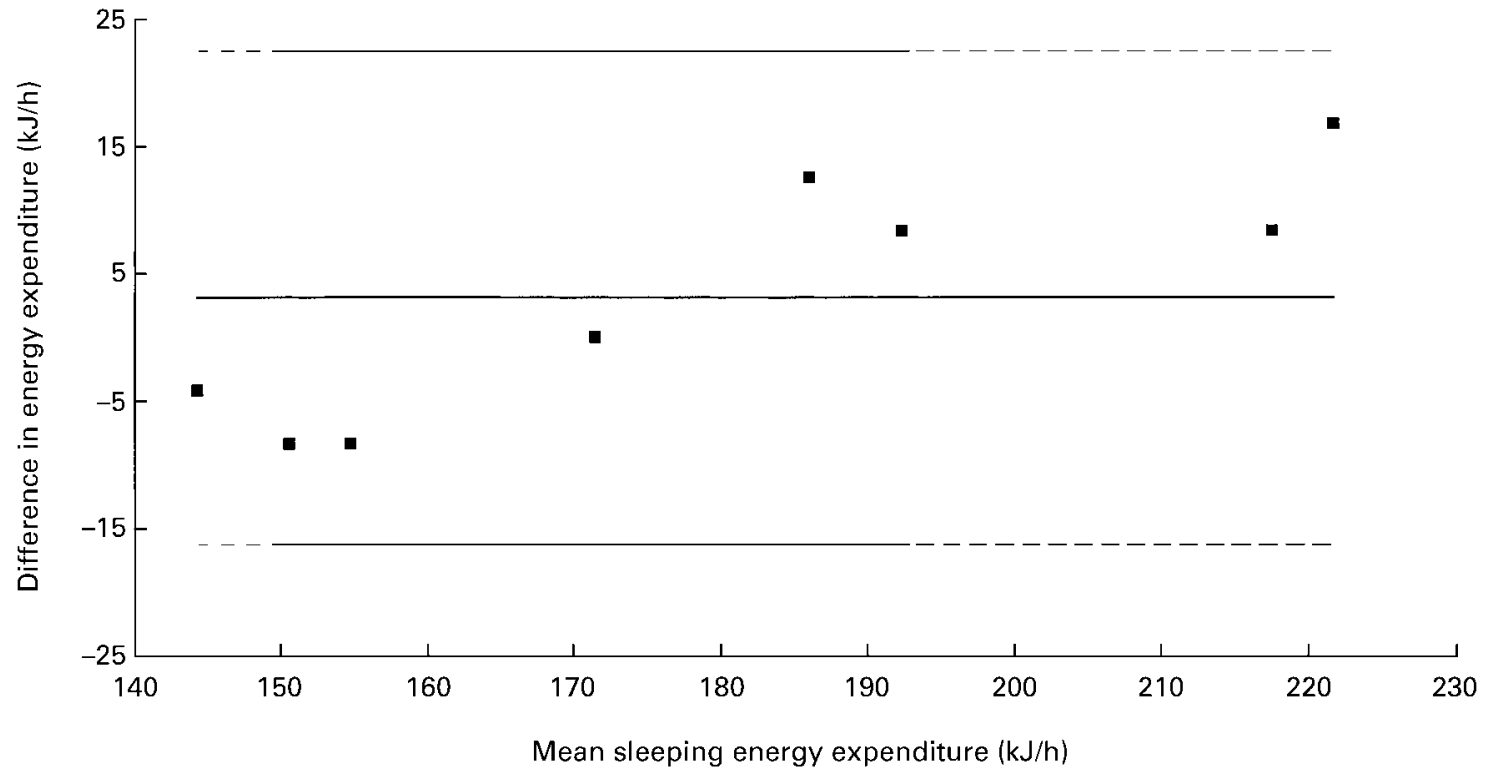

Fig. 2. Bland-Altman plot of the difference between sleeping energy expenditure measured by open-circuit indirect calorimetry and resting energy expenditure $\times 0.90$. - Mean difference between the measured and computed values during the total calibration period; --, upper and lower limits of agreement, calculated as the mean difference \pm 2 SD $r$ 0.99, $P<0.001$. For details of subjects and procedures, p. 534 .

24.00 and 04.00 hours with the higher changes in sleep stages. We considered that the period of 22.00 to 04.00 hours was representative and provided the largest range of sleeping EE values in children $<13$ years of age.

As in our previous study (Béghin et al. 2000), we used a P3 equation to compute total EE from HR data. The P3 equation was constructed by a calibration procedure with a cycle ergometer. The use of a cycle ergometer in HR monitoring has been validated against the doubly-labelled water technique with a good accuracy in the study population (Livingstone et al. 1992; Bitar et al. 1996; Treuth et al. 1998). However, the use of polynomial or linear regression equations in our present study overestimated sleeping EE as assessed by HR monitoring, as shown

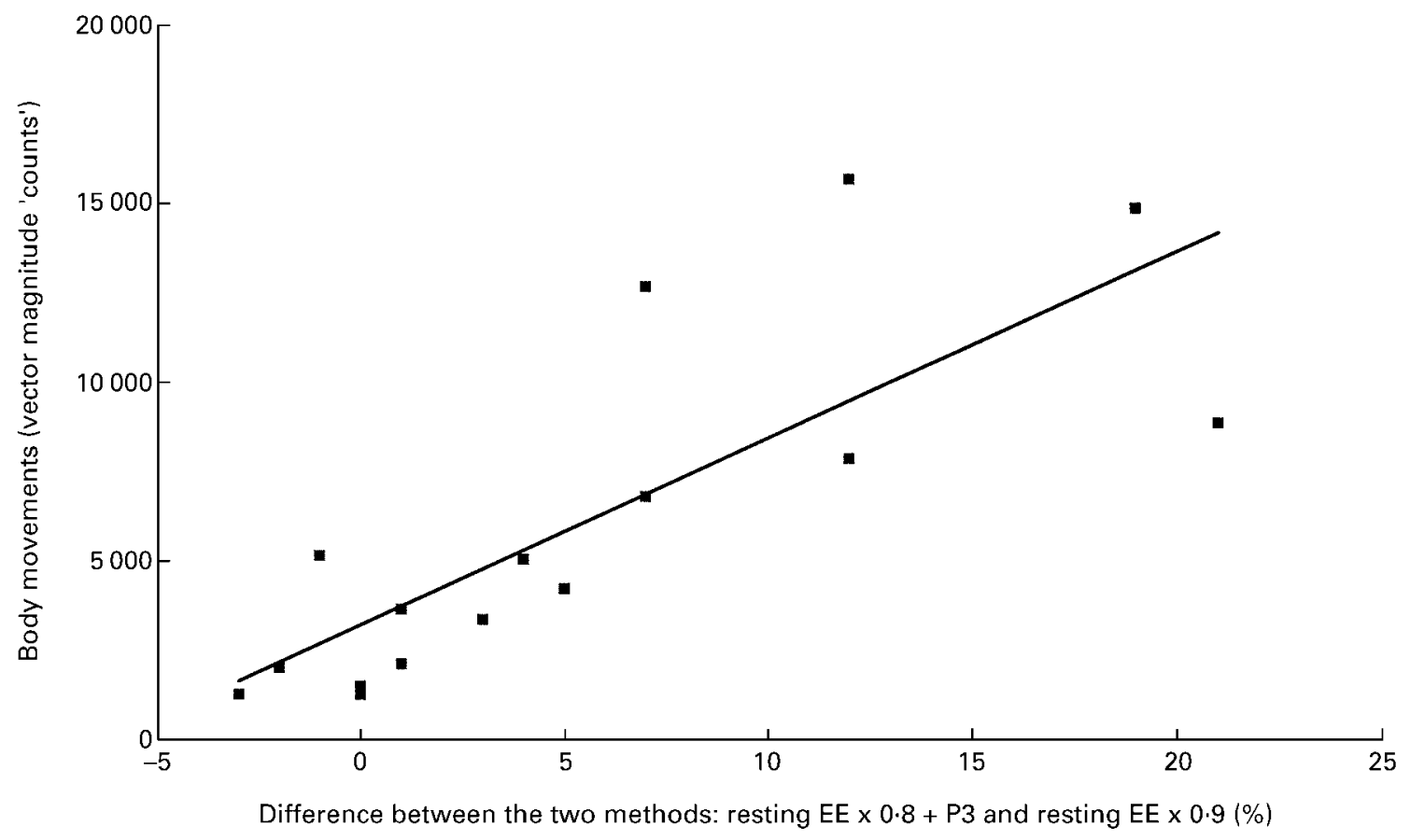

Fig. 3. Correlation between body movement and the difference of both methods of calculation of sleeping energy expenditure $(\mathrm{EE})$ in sixteen children (resting $\mathrm{EE} \times 0.90$ and resting $\mathrm{EE} \times 0.80+$ third order polynomial equation (P3)). $y=0.0012 x-1.902 ; r 0.79, P<0.05$. For details of subjects and procedures, p. 534. 
Table 2. Comparison of sleeping energy expenditure (EE) assessed with the 'resting EE $\times 0.8+$ third order polynomial equation' and 'resting EE $\times 0.9$ ' equation according to body movements during sleep $\neq$

\begin{tabular}{|c|c|c|c|c|}
\hline & \multirow{2}{*}{$\begin{array}{l}\text { Body movements during sleep } \\
\text { (vector magnitude 'counts') }\end{array}$} & \multicolumn{2}{|c|}{ Calculation of sleeping $E E(k J / h)$} & \multirow[b]{2}{*}{ Difference (\%) } \\
\hline & & Resting $\mathrm{EE} \times 0.8+\mathrm{P} 3$ & Resting EE $\times 0.9$ & \\
\hline \multirow[t]{10}{*}{$<6000$} & 1254 & 171.5 & 171.5 & 0 \\
\hline & 1259 & $121 \cdot 3$ & 125.5 & -3 \\
\hline & 1489 & $200 \cdot 8$ & $200 \cdot 8$ & 0 \\
\hline & 2014 & $175 \cdot 7$ & 179.9 & -2 \\
\hline & 2108 & $121 \cdot 3$ & $117 \cdot 2$ & 1 \\
\hline & 3359 & 238.5 & 230.1 & 3 \\
\hline & 3646 & $142 \cdot 3$ & $142 \cdot 3$ & 1 \\
\hline & 4227 & 179.9 & 171.5 & 5 \\
\hline & 5046 & 192.5 & $184 \cdot 1$ & 4 \\
\hline & 5146 & $200 \cdot 8$ & $200 \cdot 8$ & -1 \\
\hline Mean & $2954 \cdot 8$ & 174.5 & $172 \cdot 4$ & $0.8 \dagger$ \\
\hline SD & $1528 \cdot 8$ & $37 \cdot 3$ & $35 \cdot 4$ & $2 \cdot 6$ \\
\hline \multirow[t]{6}{*}{$<6000$} & 6807 & $188 \cdot 3$ & $175 \cdot 7$ & 7 \\
\hline & 7870 & 246.9 & $217 \cdot 6$ & 12 \\
\hline & 8866 & $230 \cdot 1$ & $184 \cdot 1$ & 21 \\
\hline & 12975 & $150 \cdot 6$ & 138.1 & 7 \\
\hline & 14877 & 221.8 & 179.9 & 19 \\
\hline & 15684 & $163 \cdot 2$ & $146 \cdot 4$ & 12 \\
\hline Mean & 11179.9 & $200 \cdot 1$ & 173.6 & $13 \cdot 0^{*}$ \\
\hline SD & $3810 \cdot 8$ & $38 \cdot 7$ & $28 \cdot 6$ & 5.9 \\
\hline \multicolumn{5}{|l|}{ Total } \\
\hline Mean & $6020 \cdot 4$ & $184 \cdot 1$ & $172 \cdot 9$ & $5 \cdot 4^{\star}$ \\
\hline SD & 4783.2 & $38 \cdot 7$ & $32 \cdot 0$ & $7 \cdot 3$ \\
\hline
\end{tabular}

P3, third order polynomial equation.

${ }^{*} P<0.05$ (wilcoxon rank test).

$\dagger$ NS.

$\ddagger$ For details of subjects and procedures, see p. 534 .

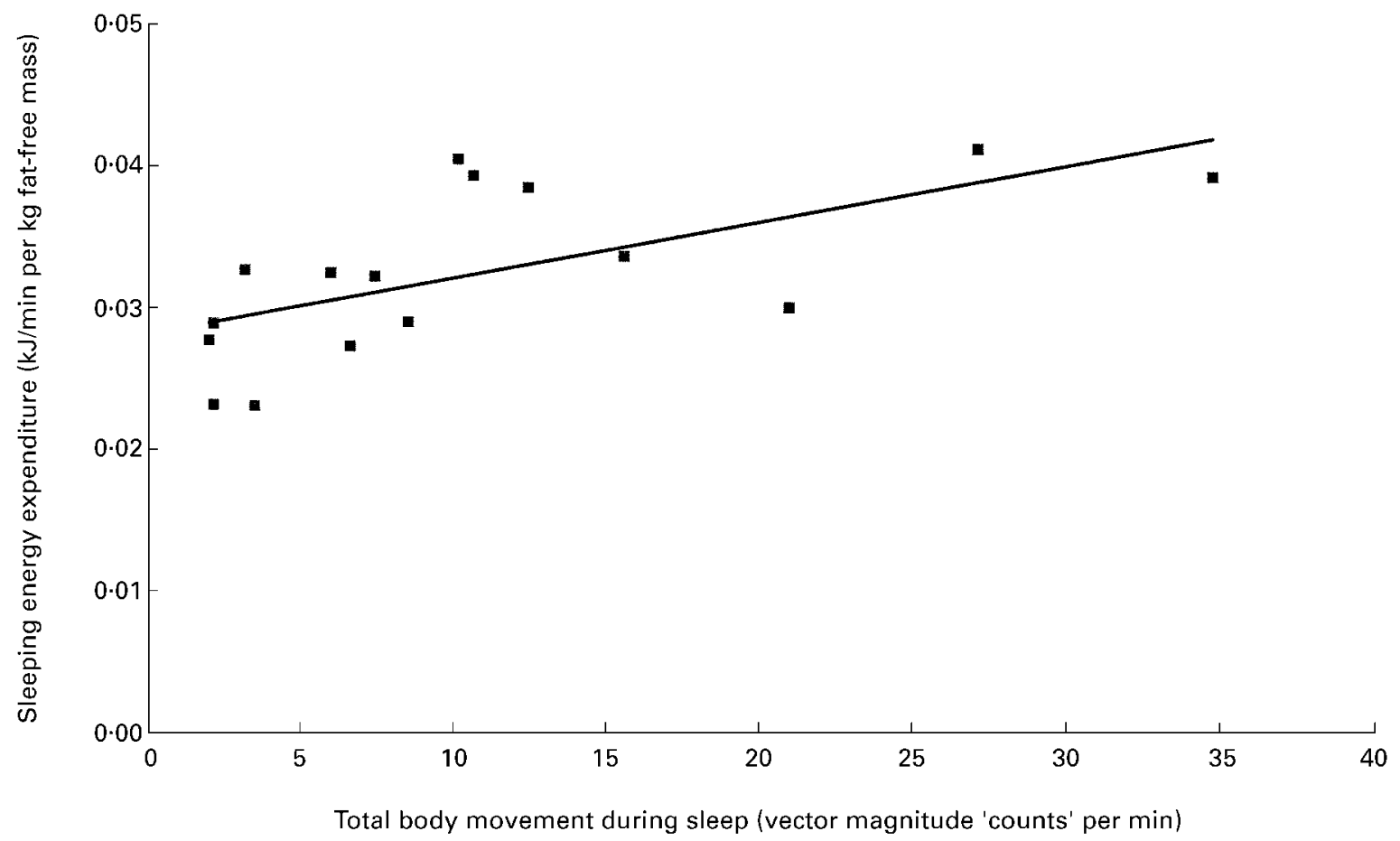

Fig. 4. Correlation between body movement and sleeping energy expenditure in sixteen children. $y=0.004 x+0.03 ; r 0.63$, $P<0.01$. For details of subjects and procedures, p. 534 . 


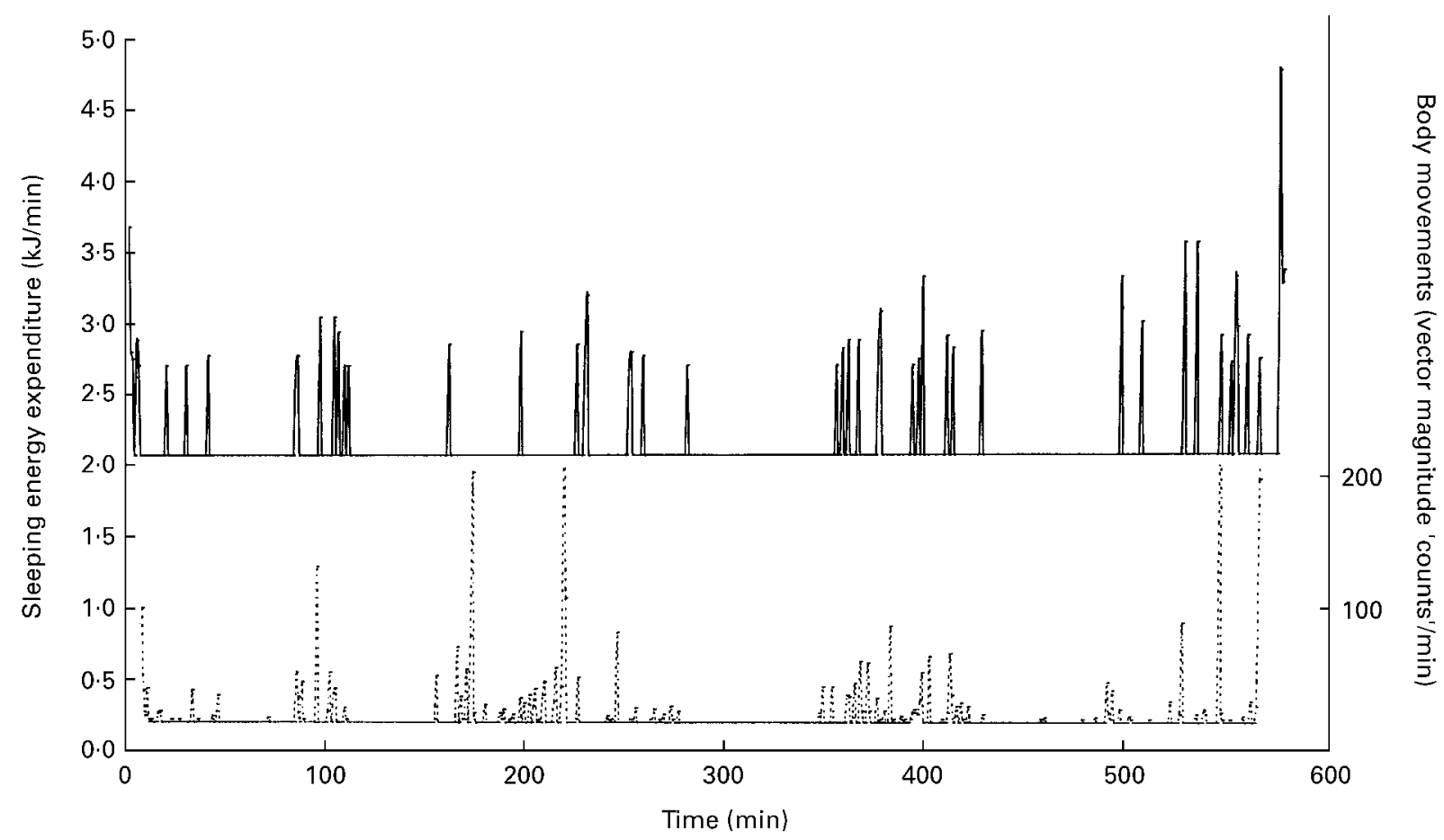

Fig. 5. Patterns of sleeping energy expenditure computed by the new methods and body movements during sleep in a representative subject (other than that in Fig. 1). - , Sleeping energy expenditure (kJ/min); --, body movements (vector magnitude 'counts' per min). For details of procedures, p. 534.

previously by Bitar et al. (1996) and Beghin et al. (2000). So, the introduction of an IP as shown in Fig. 1 and using resting $\mathrm{EE} \times 0 \cdot 8$ when $\mathrm{HR}<\mathrm{IP}$ and the P3 equation when HR > IP improved the sleeping EE assessment. The mean difference between this method and measured sleeping EE was indeed only $1 \%$. We think, therefore, that the more precise the method of calculation of sleeping EE, the more accurate will be the assessment of total EE with the HR monitoring method.

Our present study cannot be considered as a validation study, since we might have validated the new algorithm method against the same reference method using an independent second group of subjects. However, we tested this formula in an independent subset of sixteen control subjects, but compared the results with sleeping EE computed by the previous method (sleeping $\mathrm{EE}=$ resting $\mathrm{EE} \times 0.90)($ Table 2$)$ as a reference method, instead of IC as a reference method. Indeed, measurement of sleeping EE by indirect calorimetry using the Deltatrac II (Datex Instrumentation Corporation) is difficult to do for an entire night (for technical reasons, tolerance and acceptance by the child) and cannot be carried out when children are moving during sleep (loss of flow could occur during the measurement). So, we decided to use resting EE $\times$ 0.90 as the reference method to compare the new mode of calculation resting $\mathrm{EE} \times 0.80$ if $\mathrm{HR}<\mathrm{IP}$ or $\mathrm{P} 3$ if HR $>$ IP. Differences between sleeping EE computed with the formula resting $\mathrm{EE} \times 0.90$ and sleeping EE computed with resting $\mathrm{EE} \times 0.80$ when $\mathrm{HR}<\mathrm{IP}$ and $\mathrm{P} 3$ when $\mathrm{HR}>\mathrm{IP}$ during sleeping periods were increased when body movement increased. The correlation between differences between two methods and body movement was
Table 3. Comparison of total energy expenditure (EE) measured by different methods in children*

\begin{tabular}{|c|c|c|c|}
\hline \multirow[b]{2}{*}{ Age (years) } & \multicolumn{2}{|c|}{ Calculation of total EE $(\mathrm{kJ} / \mathrm{d})$} & \multirow[b]{2}{*}{$\Delta(\%) \dagger$} \\
\hline & $\begin{array}{c}\text { Resting } \\
\mathrm{EE} \times 0.8+\mathrm{P} 3\end{array}$ & $\begin{array}{c}\text { Resting } \\
E E \times 0.9\end{array}$ & \\
\hline $4 \cdot 2$ & 4005 & 3989 & 0.4 \\
\hline $5 \cdot 0$ & 5269 & 5023 & 4.9 \\
\hline $5 \cdot 2$ & 5246 & 5107 & $2 \cdot 7$ \\
\hline $5 \cdot 6$ & 5353 & 4716 & 13.5 \\
\hline $5 \cdot 6$ & 5229 & 5128 & $2 \cdot 0$ \\
\hline $6 \cdot 2$ & 4762 & 4742 & 0.4 \\
\hline $6 \cdot 3$ & 5559 & 5451 & $2 \cdot 0$ \\
\hline 6.5 & 5965 & 5061 & 17.9 \\
\hline $6 \cdot 8$ & 7533 & 7317 & 2.9 \\
\hline $7 \cdot 2$ & 7031 & 7066 & -0.5 \\
\hline 7.4 & 7317 & 6317 & $15 \cdot 8$ \\
\hline 7.5 & 7961 & 7859 & $1 \cdot 3$ \\
\hline $8 \cdot 1$ & 6895 & 6802 & 1.4 \\
\hline $9 \cdot 2$ & 6865 & 6798 & 1.0 \\
\hline $9 \cdot 2$ & 7157 & 7195 & -0.5 \\
\hline $9 \cdot 3$ & 7237 & 7249 & -0.2 \\
\hline 9.4 & 9831 & 9527 & $3 \cdot 2$ \\
\hline 10.5 & 8117 & 8034 & 1.0 \\
\hline 11.3 & 8034 & 7283 & $10 \cdot 3$ \\
\hline 11.4 & 9818 & 9737 & 0.8 \\
\hline 11.5 & 7903 & 7400 & $6 \cdot 8$ \\
\hline 11.6 & 7612 & 7157 & 6.4 \\
\hline $12 \cdot 0$ & 8247 & 8171 & 0.9 \\
\hline $12 \cdot 1$ & 9700 & 9701 & 0.0 \\
\hline Mean & 7027 & 6785 & 3.9 \\
\hline SD & 1598.3 & $1625 \cdot 7$ & $5 \cdot 3$ \\
\hline
\end{tabular}

P3, third order polynomial equation.

${ }^{*}$ For details of subjects and procedures, see p. 534.

$\dagger \Delta$, Difference between total EE computed by the two methods. 
close as shown in Fig. 3. A cut-off point of body movements as $>6000$ vector magnitude 'counts' was defined according to correlation between body movements during the night and the differences between the two methods. Differences between sleeping EE computed with the formula resting $\mathrm{EE} \times 0.90$ and sleeping EE computed with resting $\mathrm{EE} \times$ 0.80 when $\mathrm{HR}<\mathrm{IP}$ and $\mathrm{P} 3$ when $\mathrm{HR}>\mathrm{IP}$ during sleeping period gave no significant difference $(0.8$ (SD 2.6) \%) for less active sleeping children ( $n 10$ of 16 subjects), but significant difference (13 (SD 5.9) \%) for active children ( $n 6$ of 16 subjects). The difference between the methods was significantly $>5 \%$. Analysis of data in less active subjects (body movement $<6000$ vector magnitude 'counts' during sleep) showed that the mean difference decreased to $<1 \%$. As FFM is the most determinant of EE, sleeping $\mathrm{EE}$ was expressed as $\mathrm{kJ} / \mathrm{min}$ per $\mathrm{kg}$ FFM (Zhang et al. 2002). The difference between the two methods and body movement was close, because of the high correlation between body movement and sleeping $\mathrm{EE}(\mathrm{kJ} / \mathrm{min}$ per $\mathrm{kg}$ FFM) as shown in Fig. 4 for sixteen children (Spearman test, $P<0 \cdot 01$ ).

These results show that using the new formula sleeping $\mathrm{EE}=$ resting $\mathrm{EE} \times 0.80$ when $\mathrm{HR}<\mathrm{IP}$ and the $\mathrm{P} 3$ equation when HR $>$ IP gave results for sleeping EE similar to the resting $E E \times 0.90$ equation only for less active subjects. However, the use of the resting $\mathrm{EE} \times 0.90$ equation to assess sleeping EE does not take into account factors influencing sleeping EE, such as body movements during sleep, and is only an average of sleeping EE for motionless children. Although not validated in this situation, accelerometry was used to detect body movement during sleep. Fig. 5 shows the high correlation between sleeping EE pattern and sleeping body movements assessed by a TriTrac-R3D accelerometer (Professional Products) for a representative subject. To the best of our knowledge, there is no reference to validate the use of accelerometry to detect body movement during sleep. Sleeping EE computed by the new method was often higher than the resting $\mathrm{EE} \times 0.80$ baseline when body movement was detected. These results confirm the influence of body movement on sleeping EE and show that sleeping EE will be better computed by the new formula described earlier.

Another important factor in assessing total EE in freeliving conditions is that the investigator cannot be present all the time and cannot determine exactly the time spent in sleep. The starting time of sleep is often unreliable; children move a lot before sleeping and cannot recall exactly the time they start to sleep. Thus, the use of the resting $\mathrm{EE} \times 0.90$ equation during this period is inadequate and underestimates EE if the child is moving. The use of the new procedure is a good approach when using an IP. The IP separates periods without body movement during which $\mathrm{HR}<\mathrm{IP}$ and sleeping $\mathrm{EE}=$ resting $\mathrm{EE} \times 0.80$ and periods of body movement when HR $>$ IP and P3 is used.

Based on our present results, we suggest the use of this new procedure for evaluating total EE: during the night, sleeping $\mathrm{EE}=$ resting $\mathrm{EE} \times 0.80$ when $\mathrm{HR}<\mathrm{IP}$ and $\mathrm{P} 3$ when $\mathrm{HR}>\mathrm{IP}$; during the day, diurnal $\mathrm{EE}=$ resting $\mathrm{EE}$ when $\mathrm{HR}<\mathrm{IP}$ and P3 when $\mathrm{HR}>\mathrm{IP}$.

Our present results were presented according to age and compared with two other studies using the doubly- labelled water and HR methods (Livingstone et al. 1992; Fontvielle et al. 1993). The impact of this new method of calculation of sleeping $\mathrm{EE}$ on total $\mathrm{EE}$ is low, since total EE computed with the 'resting $\mathrm{EE} \times 0.80$ plus P3' and 'resting $\mathrm{EE} \times 0.90$ ' mode of calculation were close with a difference of 3.9 (SD 5.3) \%. However, the impact of our new method on total EE results was important for a subset of children with differences reaching $17.9 \%$ for some of them. These differences were observed in four subjects where body movements during the sleeping period were high.

Moreover, this new method takes into account that variation of HR during sleep could have an important impact on sleeping EE assessment in some groups of patients: children treated with enteral or parenteral nutrition (where energy is usually infused during the night into children at home) or in children who have important body movements during sleep (sleep disturbance, neurological, genetic or psychiatric diseases). Validation studies against whole-body IC in a larger sample should confirm this approach.

\section{Acknowledgements}

We thank the children and their parents for taking part in this study. This study was carried out in the Clinical Investigation Centre of Medicine, University Hospital Lille (CIC-9301-INSERM-CHU). Financial support was given by the French Ministry of Health (PHRC 1997; no. 1901).

\section{References}

Astrup A, Thorbek G, Lind J \& Isaksson B (1990) Prediction of 24-h energy expenditure and its components from physical characteristics and body composition in normal-weight humans. American Journal of Clinical Nutrition 52, 777-783.

Azaz Y, Fleming PJ, Levine M, McCabe R, Stewart A \& Johnson $\mathrm{P}$ (1992) The relationship between environmental temperature, metabolic rate, sleep state and evaporative water loss in infants from birth to three months. Pediatric Research 32, 417-423.

Beghin L, Budniok T, Vaksmann G, Boussard-Delbecque L, Michaud L, Turck D \& Gottrand F (2000) Simplification of the method of assessing daily and nightly energy expenditure in children, using heart rate monitoring calibrated against open circuit indirect calorimetry. Clinical Nutrition 19, 425-435.

Benedict FG (1919) Energy requirements of children from birth to puberty. Boston Medical and Surgical Journal 6, 107-138.

Bitar A, Vermorel M, Fellmann N, Bedu M, Chamoux A \& Coudert J (1996) Heart rate recording method validated by whole-body indirect calorimetry in 10-yr-old children. Journal of Applied Physiology 81, 1169-1173.

Bitar A, Vernet J, Coudert J \& Vermorel M (2000) Longitudinal changes in body composition, physical capacities and energy expenditure in boys and girls during the onset of puberty. European Journal of Clinical Nutrition 39, 157-163.

Bitar A, Vermorel M, Fellmann N \& Coudert J (1995) Twentyfour-hour energy expenditure and its components in prepubertal children as determined by whole-body indirect calorimetry and compared with young adults. American Journal of Clinical Nutrition 62, 308-315.

Bland JM \& Altman DG (1986) Statistical methods for assessing 
agreement between two methods of clinical measurement. Lancet 1, 307-310.

Bouten CVC, Koekkoek KTM, Verduin M, Kodde R \& Janssen JD (1997) A triaxial accelerometer and portable data processing unit for the assessment of daily physical activity. IEEE Biomedical Engineering 38, 211-229.

Bouten CVC, Westerterp KR, Verduin M, Kodde R \& Janssen JD (1994) Assessment of energy expenditure for physical activity using a triaxial accelerometer. Medicine and Science in Sports and Exercise 26, 1516-1523.

Bracco D, Morin O, Liang H, Jéquier E, Borger AG \& Schutz Y (1996) Changes in sleeping and basal energy expenditure and substrate oxidation induced by short term thyroxin administration in man. Obesity Research 4, 213-219.

Brebbia DR \& Altshuler KZ (1965) Oxygen consumption rate and electroencephalographic stage of sleep. Science 150, $1621-1623$.

Brebbia DR \& Altshuler KZ (1968) Stage-related patterns and nightly trends of energy exchange during sleep. In Computers and Electronics Devices in Psychiatry, pp. 319-335 [NS Kline and E Luska, editors]. New York: Grune \& Stratton.

Butte NF, Jensen CL, Moon JK, Glaze DG \& Frost JD (1992) Sleep organisation and energy expenditure of breast-fed and formula-fed infants. Pediatric Research 32, 514-519.

Coleman KJ, Saelens BE, Wiedrich-Smith MD, Finn JD \& Epstein LH (1997) Relationships between TriTrac-R3D vectors, heart rate, and self-report in obese children. Medicine and Science in Sports and Exercise 29, 1535-1542.

Eccles MP, Cole TJ \& Whitehead RG (1989) Factors influencing sleeping metabolic rate in infants. European Journal of Clinical Nutrition 43, 485-492.

Emons HJG, Gronenboom DC, Westerterp KR \& Saris WHM (1992) Comparison of heart rate monitoring combined with indirect calorimetry and the doubly labelled water $\left({ }^{2} \mathrm{H}_{2}^{18} \mathrm{O}\right)$ method for the measurement of energy expenditure in children. European Journal of Applied Physiology 65, 99-103.

Fontvieille AM, Harper IT, Ferraro RT, Spraul M \& Ravussin E (1993) Daily energy expenditure by five-year-old children, measured by doubly labeled water. Journal of Pediatrics 123, 200-207.

Fontvieille AM, Rising R, Spraul M, Larson DE \& Ravussin E (1994) Relationship between sleep stage and metabolic rate in humans. American Journal of Physiology 267, E732-E737.

Geissler CA, Dzumbira TMO \& Noor M (1986) Validation of a field technique for the measurement of energy expenditure: factorial method versus continuous respirometry. American Journal of Clinical Nutrition 44, 496-502.

Goldberg GR, Prentice AM, Davies HL \& Murgatroyd PR (1988) Overnight and basal metabolic rate in men and women. European Journal of Clinical Nutrition 42, 137-144.

Haskell EH, Palca JW, Walker JM, Berger RJ \& Heller HC (1981) Metabolism and thermoregulation during stages of sleep in humans exposed to heat and cold. Journal of Applied Physiology 51, 948-954.

Hull D, McArthur AJ, Pritchard K \& Goodall M (1996) Metabolic rate of sleeping infants. American Journal of Disease in Childhood 75, 282-287.

Jakicic JM, Winters C, Lagally K, Ho J, Robertson RJ \& Wing RR (1999) The accuracy of the TriTrac-R3D accelerometer to estimate energy expenditure. Medicine and Science in Sports and Exercise 31, 747-753.

Karlberg P (1952) Determination of standard energy metabolism (basal metabolism) in normal infants. Acta Paediatrica Scandinavica 41, 89-92.

Klausen B, Toubro S \& Astrup A (1997) Age and sex effects on energy expenditure. American Journal of Clinical Nutrition 65, 895-907.
Livingstone MBE, Coward WA, Prentice AM, Davies PSW, Strain JJ, McKenna PG, Mahonet CA, White JA, Stewart CM \& Kerr MJJ (1992) Daily energy expenditure in free-living children: comparison of heart-rate monitoring with the $\left({ }^{2} \mathrm{H}_{2}^{18} \mathrm{O}\right)$ doubly labelled water method. American Journal of Clinical Nutrition 56, 343-352.

Maffeis C, Pinelli L, Zaffanello M, Schena F, Iacumin P \& Schutz Y (1995) Daily energy expenditure in free living conditions in obese and non-obese children: comparison of doubly labelled water $\left({ }^{2} \mathrm{H}_{2}^{18} \mathrm{O}\right)$ method and heart-rate monitoring. International Journal of Obesity 19, 671-677.

Masse LC, Fulton JE, Watson KL, Heesch KC, Kohl HW 3rd, Blair SN \& Tortolero SR (1999) Detecting bouts of physical activity in a field setting. Research Quarterly for Exercise and Sport 70, 212-219.

Palca JW, Walker JM \& Berger RJ (1986) Thermoregulation, metabolism, and stages of sleep in cold-exposed men. Journal of Applied Physiology 61, 940-947.

Panter-Brick C, Todd A, Baker R \& Worthman C (1996a) Comparative study of flex heart rate in three samples of Nepali boys. American Journal of Human Biology 8, 653-660.

Panter-Brick C, Todd A, Baker R \& Worthman C (1996b) Heart rate monitoring of physical activity among village school, and homeless Nepali boys. American Journal of Human Biology $\mathbf{8}$, 661-672.

Rechtschaffen A \& Kales A (1968) A Manual of Standardized Terminology, Techniques and Scoring System for Sleep Stages of Human Subjects. National Institutes of Health Publication 204. Washington, DC: US Government Printing Office.

Ryan T, Mlynczak S, Erickson T, Man SFP \& Man GCW (1989) Oxygen consumption during sleep: Influence of sleep stage and time of night. Sleep 12, 201-210.

Schaefer F, Georgi M, Zieger A \& Scharer K (1994) Usefulness of bioelectric impedance and skinfold measurements in predicting fat-free mass derived from total body potassium in children. Pediatric Research 35, 617-624.

Schofield WN (1985) Predicting basal metabolic rate, new standards and review of previous work. Human Nutrition: Clinical Nutrition 39, Suppl. 1, 5-41.

Schutz Y \& Deurenberg P (1996) Energy metabolism: overview of recent methods used in human studies. Annals of Nutrition and Metabolism 40, 183-193.

Sempé M, Pedron G \& Roy-Pernot MP (1979) Auxologie: methods et sequences, pp. 25-49. Paris: Théraplix.

Spurr GB, Reina JC \& Barac-Nieto M (1986) Marginal malnutrition in school-aged Colombian boys: metabolic rate and estimated daily energy expenditure. American Journal of Clinical Nutrition 44, 113-126.

Stothers JK \& Warner RM (1978) Oxygen consumption and neonatal sleep states. Journal of Physiology 278, 435-440.

Stothers JK \& Warner RM (1984) Thermal balance and sleep state in the newborn. Early Human Development 9, 313-322.

Talbot FB (1921) Standards of basal metabolism in normal infants in children. American Journal of Disease in Childhood 21, 519-528.

Torun B, Davies PSW, Livingtone MBE, Paolisso M, Sackett R \& Spurr GB (1996) Energy requirements and dietary energy recommendations for children and adolescents 1 to 18 years old. European Journal of Clinical Nutrition 50, Suppl. 1, S37-S81.

Treuth MS, Adolph AL \& Butte NF (1998) Energy expenditure in children predicted from heart rate and activity calibrated against respiration calorimetry. American Journal of Physiology 275, E12-E18.

van Mil EA, Westerterp KR, Gerver WJ, Curfs LM, SchrandeStumplel CT, Kester AD \& Saris WH (2000) Energy expenditure at rest and during sleep in children with Prader-Willi syndrome is 
explained by body composition. American Journal of Clinical Nutrition 71, 752-756.

Wareham NJ, Hennings SJ, Prenctice AM \& Day NE (1997) Feasibility of heart-rate monitoring to estimate total level and pattern of energy expenditure in a population-based epidemiological study: the Ely young cohort feasibility study 1994-5. British Journal of Nutrition 78, 889-900.

Webb P \& Hiestand M (1975) Sleep metabolism and age. Journal of Applied Physiology 38, 257-262.

Weir JB (1949) New methods for calculating metabolic rate with special reference to protein metabolism. Journal of Physiology 109, 1-9.

Welk GJ \& Corbin CB (1995) The validity of the TriTrac-R3D activity monitor for the assessment of physical activity in children. Research Quarterly for Exercise and Sport 66, 1-8.

Wells JCK \& Davies PSW (1995a) Sleeping metabolic rate and body size in 12-week-old infants. European Journal of Clinical Nutrition 49, 323-328.
Wells JCK \& Davies PSW (1995b) The effect of diet and sex on sleeping metabolic rate in 12-week-old infants. European Journal of Clinical Nutrition 49, 329-335.

Westerterp KR (1999) Physical activity assessment with accelerometers. International Journal of Obesity and Related Metabolic Disorders 23, 45-49.

White DP, Weil JV \& Zwillich CW (1985) Metabolic rate and breathing during sleep. Journal of Applied Physiology 59, 384-391.

World Health Organization (1985) Energy and Protein Requirements. Report of a Joint Food and Agriculture Organization/ World Health Organization/United Nations University Expert Consultation. World Health Organization Technical Report Series no. 724. Geneva: WHO.

Zhang K, Sun M, Werner P, Kovera AJ, Albu J, Pi-Sunyer FX \& Boozer CN (2002) Sleeping metabolic rate in relation to body mass index and body composition. International Journal of Obesity 26, 376-383. 